\title{
Emotional Intelligence and its Association with Motivational Levels and Perception of Pain during Orthodontic Treatment
}

\author{
Ashwathy Mohan Pillai ${ }^{a}$, Supriya Nambiar ${ }^{b}$, Unnikrishnan.B ${ }^{\mathrm{c}}$.
}

\begin{abstract}
Introduction: During orthodontic treatment pain is experienced by the patient but here the stimulus is not withdrawn, so the pain and discomfort continues throughout the duration of treatment. Patient's ability to withstand this constant and continuous pain and discomfort depends a great deal on the emotional quotient of the patient .Aims \&Objectives: To record the emotional quotient and assess the relation between emotional intelligence and perception of pain during orthodontic treatment. Also, to find out the relation between emotional intelligence and the patient motivational level for orthodontic treatment. Methodology: The study was designed as a cross sectional prospective research on a sample of 30 participants between 15-25 yrs. The patients were asked to fill the questionnaire the next day of separator placement along with the Visual Analog Scale (VAS). Trait Emotional Intelligence Questionnaire-Short Form (TEIQue-SF) was used. Results: The results showed no significant correlation between EQ and pain when compared in general but was negatively correlated and significant for males when compared separately for males and females.. Conclusion: The findings of the study clearly emphasizes the importance of a patient's motivation for orthodontic treatment. It also reveals the importance of Emotional Quotient to tolerate the pain experienced during the orthodontic treatment.
\end{abstract}

Index Terms- Orthodontic treatment; Emotional Intelligence, Pain; separators.

\section{INTRODUCTION}

Orthodontic treatment is undertaken by the general population for various reasons like better aesthetics, correction of malocclusion, trauma of teeth and periodontium, due to malocclusion and the treatment usually lasts for 1-2 years [1], [2]. Patient's motivation to undergo orthodontic treatment is mainly based on some subjective factors such as self-perception of dental condition and aesthetics as well as based on the patient's knowledge about the treatment. During the period of treatment, patient is most likely to experience significant amount of pain which is observed to be greater in girls when compared to boys and varies from one individual to another. Pain is subjective and different studies show variations in perception of orthodontic pain with age, gender and use of analgesics [3], [4].

Pain is in generally defined as an unpleasant physical or mental feeling due to some stimulus which usually subsides

a. Ashwathy Mohan Pillai, Undergraduate student ,Manipal College of Dental Sciences, Mangalore, Manipal Academy of Higher Education, Manipal 576104. India (e-mail: ashwathymohanpillai@gmail.com).

b. Supriya Nambiar, Assoc.Professor, Dept of Orthodontics, Manipal College of Dental Sciences, Mangalore, Manipal Academy of Higher Education, Manipal 576104. India (e-mail: Supriya.nambiar@manipal.edu). c. Unnikrishnan.B, Assoc. Dean \& Professor, Dept of Community Medicine, Kasturba Medical College , Mangalore, Manipal Academy of Higher Education, Manipal 576104. India (e-mail: Unnikrishnan.B@manipal.edu) once it is removed. During orthodontic treatment, a particular amount of pain is experienced by the patient but here the stimulus (treatment) is not withdrawn and so the pain and discomfort continues throughout the duration of treatment period. Hence this pain experienced during the treatment becomes significant and patient's ability to withstand this constant and continuous pain and discomfort depends a great deal on the Emotional quotient (EQ) of the patient and therefore is of relevant to the orthodontic fraternity. Emotional intelligence (EI) is the ability to monitor one's own and other's emotions, to discriminate between different emotions and label them appropriately and to use emotional information to guide thinking and behavior [5]. It includes five important categories of abilities which are self-awareness which is the ability to know one's own feelings, self-regulation which is the ability to control one's emotions and become flexible when required, motivation which is the ability to help oneself move forward in life, empathy which is the ability to accurately understand what other's feel and social skills which is required to be in a respectful position in one's society. Psychologists state that Intelligence quotient (IQ) plays only an average of $10 \%$ and rest all success of life depends on one's EQ [6]. Emotional intelligence is based on three models: ability model, mixed model and the trait model proposed by Konstantinos Vasilis Petrides. The trait model is based on the self-perceptions of their emotional abilities [7]. Trait EI is investigated within a personality framework as it denotes the actual lower levels of personality. An increased score of emotional quotient might be significant as it can indicate the overall ability of an individual to carry out things in a better way than one with a lower EQ [8]. Individuals with higher EQ are believed to perform better in their jobs, have good social behavior, empathy, planning and better memory. Their selfesteem is generally high and has better cognitive abilities. This research is intended to find out the effect of emotional quotient on patient's motivational levels and tolerance to pain and further help in understanding relation between one's EQ and orthodontic treatment (motivation and pain).

The main objectives of the study were as follows:

1. To record the emotional quotient and to assess the relation between emotional intelligence and perception of pain during orthodontic treatment.

2. To find out the relation between emotional intelligence and patient motivational levels for orthodontic treatment. 


\section{II.METHODOLOGY}

The study was designed as a cross sectional prospective research on a sample of 30 participants after non probability sampling method. The age group of individuals was between 15-25 years and the study duration was set at 2 months extending from May-June 2015.The inclusion criteria were subjects who were in the initial phases of planning for orthodontic treatment with no previous history of orthodontic treatment and a good general health. As exclusion criteria, subjects who were on psychotropic drugs and analgesics, presence of retained deciduous teeth, impacted teeth, history of previous orthodontic treatment, usage of anti-inflammatory drugs; dental students were excluded as it may vary the findings of the study. The data was collected from the study subjects who came to the outpatient section of Orthodontics department for treatment. They were informed about the objective of the study and after obtaining informed written consent, were recruited into the study. The subjects were administered a questionnaire for assessing their emotional quotient (EQ) and pain at the time of separator placement appointment. The patients were asked to fill the questionnaire the next day of separator placement along with the Visual Analog Scale (VAS) for pain and motivational level assessment. The socio demographic profile of the participants was also assessed in the questionnaire.

The most commonly used scale to assess the intensity of pain in researches is the Visual Analog Scale (VAS), (Figure: 1) Woodforde and Merskey used VAS pain scale initially with two extremes of "no pain at all" and "my pain is as bad as it could possibly be" in patients with a variety of conditions [9]. Here also VAS was used to evaluate the intensity of pain when the patient underwent an orthodontic treatment. It is a single item scale. The patient marks on the horizontal line the point that they feel represents their perception of their current state. The VAS score was determined by measuring the distance in millimeters from the left hand end of the line to a point that the patient marks [10]. Administration of the scale is easy as it does not require any special training other than the knowledge of using a ruler. The distance must be measured accurately. VAS was well accepted by the patients also as it was not tedious ( $<1$ minute to complete).

\section{No pain $\quad$ Very severe pain}

"Fig 1." Representation of VAS

The Visual Analog Scale used to assess pain itself was used to assess the motivational levels of a patient to undergo orthodontic treatment. Patient's motivation to undergo orthodontic treatment was assessed through a 27-question questionnaire based on the works of Clemmer and Hayes [11] and Fox et al [12] , divided into 5 domains: Perceived Severity, Dental Esthetics, Willingness-to-Treat, Treatment Perception and Occlusion Importance(Table I).
TABLE I: MOTIVATIONAL LEVEL ASSESSMENT

\begin{tabular}{|c|c|c|}
\hline DOMAINS & $\begin{array}{l}\text { QUESTIO } \\
\text { NS }\end{array}$ & $\begin{array}{l}\text { VAS } \\
\text { VARIATIONS }\end{array}$ \\
\hline $\begin{array}{l}\text { Perceived } \\
\text { Severity }\end{array}$ & 1 to 7 & $\begin{array}{c}\text { Completely true } \\
\text { / Completely } \\
\text { false }\end{array}$ \\
\hline $\begin{array}{l}\text { Dental } \\
\text { esthetic }\end{array}$ & 8 to 10 & $\begin{array}{c}\text { Completely true } \\
\text { / Completely } \\
\text { false }\end{array}$ \\
\hline $\begin{array}{l}\text { Willingness- } \\
\text { to- } \\
\text { Treat }\end{array}$ & $\begin{array}{l}11 \text { to } 14 \\
15 \text { to } 16 \\
17 \text { to } 18\end{array}$ & $\begin{array}{c}\text { Completely true } \\
\text { / Completely } \\
\text { false } \\
\text { Totally disagree } \\
\text { / totally agree } \\
\text { Definitely not / } \\
\text { definitely yes }\end{array}$ \\
\hline $\begin{array}{l}\text { Treatment } \\
\text { Perception }\end{array}$ & 19 to 25 & $\begin{array}{c}\text { Totally disagree } \\
\text { / totally agree }\end{array}$ \\
\hline $\begin{array}{l}\text { Occlusion } \\
\text { Importance }\end{array}$ & 26 to 27 & $\begin{array}{c}\text { Without } \\
\text { importance / } \\
\text { very important }\end{array}$ \\
\hline
\end{tabular}

The subjects were instructed to fill the questionnaire without providing any further information on the questions. The VAS value was calculated in the same way as it was done for pain scale; that is the distance in millimeters from the left end of the horizontal line to the point made by the patient will be measured. The value for each domain was elicited from the arithmetic mean of the corresponding answers [13]. There are many selfreport measures of trait EI some of which include EQ-i, the Swinburne University Emotional Intelligence Test (SUEIT), and the Schutte EI model but these are limited measures of trait EI [14]. Trait Emotional Intelligence Questionnaire (TEIQue) is comprehensive and specifically designed for measuring trait EI. Many forms of TEIQue are available. The general test encompasses 15 subscales put under four factors: well-being, self-control, emotionality, and sociability (Table II).

This project was carried out using Trait Emotional Intelligence Questionnaire-Short Form (TEIQue-SF) which is based on the long form of TEIQue. It included 30 items designed to measure global trait EI score and the questionnaire could be completed in approximately 7 minutes. Each item in the TEIQue had values from 1-7 denoting completely disagree to completely agree that responded to a 7-point Likert scale. The subject had to circle the score which they felt was the most appropriate. The TEIQue-SF was scored in reverse: the items were scored and then the responses were added and interpreted. The data was analyzed using statistical package SPSS version 11.0.

\section{III.RESULTS}

The study had three parts- Trait emotional intelligence questionnaire (TEI-SF), motivational levels assessed in five different domains and a Visual Analogue Scale to assess pain. The results showed no significant correlation between EQ and pain when compared in general but was negatively correlated and significant in males when compared separately for males and 
females.(Table III) There was no significant correlation when TABLE III: PEARSON CORRELATION

EQ and motivational level was compared in any of the domains.

But, when pain was compared to motivational levels all domains negatively correlated except for the significant result seen between occlusal importance domain in motivational level and pain. Descriptive statistics and Pearson's correlation was performed as depicted in Table II and III.

TABLE II: ARITHMETIC MEAN VALUES

\begin{tabular}{|c|c|c|c|c|}
\hline \multirow[t]{2}{*}{$\begin{array}{c}\text { Motivation } \\
\text { al } \\
\text { levels }\end{array}$} & \multicolumn{2}{|c|}{$\begin{array}{c}\text { Pain (VAS } \\
\text { Scale) } \\
(\text { Mean }= \\
3.9350) \\
(\mathrm{SD}=2.50479)\end{array}$} & \multicolumn{2}{|c|}{$\begin{array}{c}\text { Emotional } \\
\text { intelligence } \\
(\text { Mean }= \\
140.3333) \\
(\mathrm{SD}= \\
16.14873)\end{array}$} \\
\hline & $\begin{array}{c}\text { Pearson } \\
\text { correlat } \\
\text { ion }\end{array}$ & Sig. & $\begin{array}{c}\text { Pearson } \\
\text { correlat } \\
\text { ion }\end{array}$ & Sig. \\
\hline $\begin{array}{c}\text { Perceived } \\
\text { severity } \\
(\text { Mean }= \\
43.4930) \\
(\mathrm{SD}= \\
17.34709) \\
\end{array}$ & .092 & .630 & .105 & .582 \\
\hline $\begin{array}{c}\text { Dental } \\
\text { esthetics } \\
(\text { Mean }= \\
53.2330) \\
(\mathrm{SD}= \\
28.79785)\end{array}$ & -.028 & .882 & .041 & .830 \\
\hline $\begin{array}{c}\text { Willingness } \\
\text { to treat } \\
(\text { Mean }= \\
48.7040) \\
(\mathrm{SD}= \\
19.69180)\end{array}$ & -.109 & .565 & .017 & .929 \\
\hline $\begin{array}{c}\text { Treatment } \\
\text { perception } \\
(\text { Mean }= \\
51.1983) \\
(\mathrm{SD}= \\
19.77786)\end{array}$ & .233 & .215 & .020 & .915 \\
\hline $\begin{array}{c}\text { Occlusal } \\
\text { importance } \\
(\text { Mean }= \\
73.6083) \\
(\mathrm{SD}= \\
21.01351)\end{array}$ & $-.415\left(^{*}\right)$ & .023 & .319 & .086 \\
\hline
\end{tabular}

\begin{tabular}{|c|c|c|c|}
\hline & \multicolumn{3}{|c|}{$\begin{array}{l}\text { Pain (VAS Scale) } \\
\text { Pearson correlation }\end{array}$} \\
\hline & $\begin{array}{c}\text { Total } \\
\text { (Mean = } \\
3.9350) \\
(\mathrm{SD}= \\
2.50479)\end{array}$ & $\begin{array}{c}\text { Males } \\
\text { (Mean = } \\
3.1950) \\
(\mathrm{SD}= \\
2.54214)\end{array}$ & $\begin{array}{c}\text { Females } \\
\text { (Mean = } \\
4.3050) \\
(\mathrm{SD}= \\
2.46629)\end{array}$ \\
\hline 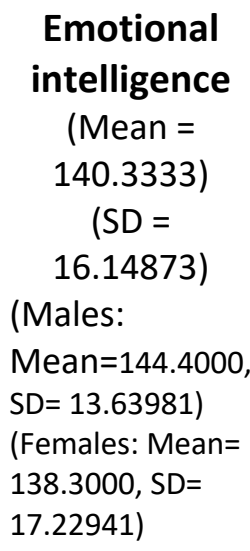 & -.111 & $-.703(*)$ & .167 \\
\hline Sig. & .560 & .023 & .482 \\
\hline
\end{tabular}

\section{IV.DISCUSSION}

A prospective study was conducted on patients undergoing orthodontic treatment to assess the relationship of EQ with pain threshold and motivational levels. The pain experienced during orthodontic treatment was assessed using VAS in which no significant correlation between EQ and pain scale was seen, but showed a significant dimorphism when compared separately for males and females. Males showed a negative correlation which is significant between EQ and pain whereas such a difference was not evident when EQ and pain was compared in females which agrees to the previous studies showing women being more stable emotionally than males [15].

A comparison between an individual's EQ and motivational levels was done under five different domains in which all the domains showed a positive correlation with EQ but high enough to be significant. There are not many studies conducted in this area and hence provides scope for more detailed study. The comparison between motivational levels and pain was studied and the results showed a negative correlation which was significant when the occlusal importance was compared to pain scale. No other domains in motivational levels showed any significant correlation with pain scale that is in complete agreement with other studies which concluded the importance of malocclusion as a factor that affects the pain experienced during treatment [16]. These results clearly emphasize the importance of the role of occlusion in determining the pain and motivational levels of an orthodontic patient. According to the results obtained from the studies, patients who considered 
occlusion to be important experienced less pain that can motivate the patient to undergo orthodontic treatment successfully as there are chances of discontinuing the treatment due to the pain experienced. The number of participants in this study is less and hence the result obtained may not be completely generalized but the study surely emphasizes the importance of patient education, malocclusion perceived by the patient and pain threshold of an individual for successful outcome of treatment.

\section{CONCLUSION}

The findings of the study clearly emphasize the importance of a patient's motivation for orthodontic treatment. It also reveals the importance of Emotional Quotient to tolerate the pain experienced during the orthodontic treatment, especially in the initial few months of treatment as the pain is maximum during this time. It is important that the patients are highly motivated, has a good pain threshold and understands and accepts the treatment for better results.

\section{IMPLICATIONS}

The knowledge gained from the study would be useful in some aspects like counseling the patients to undergo a successful orthodontic treatment, if he or she is found to have low motivational levels. This can be applied to the patients awaiting other dental treatments and also can be used to understand on how emotional intelligence can affect the motivational level to undergo an orthodontic treatment. The information from this study gives us an insight into how perception of pain and discomfort can alter with one's emotional intelligence while undergoing an orthodontic treatment.

\section{REFERENCES}

[1] D.Roberts-Harry, J. Sandy; Orthodontics. Part 1: Who needs orthodontics? British Dental Journal, 2003; 195: 433-437.

[2] DF Fink and RJ Smith," The duration of orthodontic treatment"; Am J Orthod Dentofacial Orthop. 1992; 102: 45-51

[3] P.A. Scheurer, A.R.Firestone et al ;'Perception of pain as a result of orthodontic treatment with fixed appliances "; Journal of Orthodontics, European Orthodontic Society 1996.18.

[4] DaSilva Campos.M.J, Fraga.M.R, Raposo.N.B, Ferreira.A.P et al;” Assessment of pain experience in adults and children after bracket bonding and initial arch wire insertion"; Dental Press J. Orthod. 2013. Vol.18 no.5.

[5] Coleman. A; "A Dictionary of Psychology" (3 Ed.). Oxford University Press. 2008.

[6] Akers.M, Porte.G; "What is Emotional Intelligence (EQ)?" 2007.

[7] Petrides, K.V, Pita.R. Kokkinaki, F; "The location of trait emotional intelligence in personality factor space.” British Journal of Psychology 2007, 98, 273-289.

[8] Bar-OnR.;"The Bar-On model of emotional-social intelligence (ESI)"; 2006. Psicothema, 18, sulp, 13-25.

[9] Woodforde J M, Merskey H; "Some relationships between subjective measures of pain". J Psychosom Res 1972; 16: 173-8.

[10] 10.N.Crichton ,"Visual Analogue Scale (VAS)" Blackwell Science Ltd, Journal of Clinical Nursing, 2001. 10, 697-706.

[11] Clemmer EJ, Hayes EW."Patient cooperation in wearing orthodontic headgear". Am J Orthod. 1979 P; 75(5):517-24

[12] Fox RN, Albino JE, Green LJ, Farr SD, Tedesco LA. Developmen and validation of a measure of attitudes toward malocclusion. J Dent Res. 1982; 61(9):1039-43.

[13] Da Silva Campos.M.J, Vitral.R.F;" The influence of patient's motivation on reported pain during orthodontic treatment" Dental Press J. Orthod. May/June 2013. vol.18 no.3
[14] Perez, J.C., Petrides, K.V, Furnham. A;" Measuring trait emotional intelligence", International Handbook of Emotional Intelligence 2005. Pp.181-201

[15] Barrett.L.F, Lane.R.D, Sechrest.L, and Schwartzds.G.E; "Sex Differences in Emotional Awareness", Vol, 26 issue: 9, page(s): 1027-1035

[16] Sen.S, Asrani.M, Patadiya.H, Sen.S; "Emotional intelligence: new vistas in health care"; Journal of Research in Medical and Dental Science,Vol. 1,Issue.2,Oct-Dec 2013. 